\title{
CREATIVE LAB USAGE
}

\section{Harry Reinert}

The language laboratory is an educational tool. And as with any tool, the greater the degree of sophistication of the tool, the more limited are its uses: a stone picked up from the ground might be used equally well either to crack a walnut or to drive a stake into the ground. But one would scarcely use a silversmith's delicate hammer for either task. Much of the disillusionment which has arisen in recent years regarding the usefulness of the language lab is the result of trying to use this sophisticated tool in situations for which its is not particularly well suited. Let us admit aloud that in the task of trying to teach foreign language the use of electronic paraphernalia is limited. Once we have made this honest admission, we may finally be free to discover what genuine, unique benefits may be derived from the language lab, e.g. within certain limits the lab serves admirably as $a^{/}$drill master, as $a^{2}$ source of native sounds, as $a^{3}$ means of providing additional materials for those students who are capable of using them, and as a/testing device. The limit of each of these activities is that if the teacher depends too much on the lab, the student becomes bored-at best-or actively hostile toward foreign language learning. In addition to its traditional use as a drill master, the lab can be used creatively to present a new facet to language learning and to increase student interest.

Language is a uniquely human invention, and the use of language is an activity peculiar to human beings. This obvious fact precludes the possibility of anything more than very limited success in reducing language to a set of finite elements which can be programmed into a machine. Norbert Wiener, who coined the term "cybernetics" and played a major role in the early development of automation, pointed out that machines are literal-minded: "the great weakness of the machine-the weakness which saves us from being dominated by itis that it cannot yet take into account the vast range of probability that characterizes the human situation." Viewed differently, we might think of man as equipped with a computer of almost infinite complexity and variety-the brain. One product of this infinitely varied machine is language, which does reflect "the vast range of probability that characterizes the human situation." So, if we hope to reduce language to the simple confines of a set of programmed materials or a set of tapes, we must fail. 


\section{Creative Lab}

In an article in the Saturclay Review in 1967 Peter Schrag suggested that "if nothing else, the introduction of programmed learning will demand of every teacher an answer to the question: 'What can you do that the machine can't?' " It might be more appropriate to ask "What can the machine, e.g. the larguage lab, do that the teacher should not have to do?" For example, the teacher can conduct drill sessions-and foreign language teachers have been doing this for decades, if not centuries. But when we look at the language lab as an educational tool, we see that the teacher can be relieved of some of this burden in order to use his human talents on other tasks. Then we might find uses of the lab which would answer the further question: "What can the lab do that the teacher cannot do?"

The language lab may serve two different functions: the lab may be used as the untiring drill master, and it may also be used creatively to stimulate interest and facility among the students. Far too often this expensive, sophisticated tool has been used only for drill work and its creative possibilities have been ignored.

In its function as drill master the language lab does not do anything which the teacher cannot do, but something which the teacher should not be expected to do. There has never been any doubt that the learning of any skill requires long periods of repetitious drill. In learning most skills the student is left to do his drill work privately, e.g. no one expects the music teacher to sit with his students for an hour each day while they practice scales, technical drills, and other assigned material. But the foreign language teacher has often been put in the position of having to monitor the students' drill work. The introduction of taped materials has lifted this burden from the teacher.

However, we must note that even here the lab has only limited usefulness. The unswerving tempo and invariable, untiring voices on the tape which make it so valuable as a model for drill is also its major handicap. In no sense can the drill tape ever be an adequate substitute for living contact with another person, i.e. conversation. The invariable pace of drill tapes limits their usefulness, for after the student has been through the patterns often enough to become familiar with them, the pace needs to be quickened to insure continued quick response.

Tapes provide the student the opportunity to hear native speakers. Unfortunately, however, the speech of these speakers is often so sterile that it cannot be expected to hold the student' interest. In order to have a clear and accurate model, the speakers on many tapes speak with such great care that the speech can scarcely be called natural. Here again, the tapes have value, but that value is limited by the painfully meticulous articulation which initially is so important.

This situation can be improved by seeking materials for student 
consumption which were not designed solely as pronunciation models. Children's records imported from foreign countries, for example, can often be a real boon. Such records have the benefit of trained native voices, but since they are designed for other native speakers, the delivery is clear without being forced or stilted. Also, since children's records must appeal to children, there is usually a variety of voices, plenty of sound effects to help carry meaning, and often background music to help set the mood. Equally important, such records usually have a story-a story which is simple enough for the American student to follow with interest. Materials of this sort are also available from some American distributors of audio-visual materials.

One of the most unfortunate characteristics of the various audiolingual programs has been their singular lack of humor. The basic reader which was such a staple in the traditionally oriented classroom was filled with humorous anecdotes, even at the elementary level, and with stories which could be read for their own sake. One will look in vain for such materials in most audio-lingual programs. Thus, it is small wonder that students are frequently bored-their attitude reflects the nature of the materials with which they are confronted. Whenever professionally prepared materials with some intrinsic interest, such as children's records or the like, can be presented as part of the lab program, we find an increased interest among the students. Here we have a use of the lab which the teacher cannot provide-unless we happen to find a teacher who is an especially gifted mimic.

The lab also provides the opportunity to test and evaluate the student's progress. Such testing need not and should not be limited to mere sound discriminiation. The ability to use the various structures and vocabulary introduced in the program can also be effectively evaluated in the lab. The simplest way of doing this is to devise a series of quizzes on tape which can be administered in the lab. In order to get a fair evaluation of the student's overall progress in his language study, such tests should be included, and ideally they should be multiple choice. Although the student may be required occasionally to give written answers, testing for writing skills takes us into an area which is not best handled in the lab.

Too often in recent years our testing techniques have not kept pace with our materials. Thus, it is not uncommon in audio-lingual programs to find tremendous emphasis placed on speaking and listening in the classroom work but then to see the students being graded by written tests which depend on the reading and writing skills. The lab can be used to offset the inherent unfairness of such quizzes. With multiple-choice quizzes based on the various structures within each lesson, it is possible to get some idea of how well the student understands the structures themselves. Obviously this is only one part 


\section{Creative Lab}

of a comprehensive testing program, but a part that is often overlooked.

The lab has been frequently used in its various drill master functions. However, the lab can also be used creatively. Some of the more elaborate facilities have previously made it possible for the student to hear his responses to patterns on the master tape. It is important that the student hear his own pronunciation, and it is possible to have the student read onto tape for later evaluation by the teacher. But it is more effective to have several students prepare a tape together. Even at the earliest stages of study small groups of students could perform on tape the dialog for a given lesson. Better, however, is for the student to prepare and record their own dialogs. It is already a common practice to have students construct dialogs which are variations on the basic dialog for a given lesson. But if we take this a step further and have the students record their variations on tape, we have the further advantage of giving the students the opportunity to practice their speaking in a more natural situation than when they merely repeat single phrases in isolation.

Furthermore, such tapes can be replayed for the whole class. Not only can the teacher and the students involved in the dialog evaluate the efforts of the participants, but the other students in the class should also be encouraged to become critics, noting both the strong and weak points in each dialog. If it be true that it is easier "to see the mote in thy brother's eye than the beam in thine own," the other members of the class may very well become aware of their own speech patterns more quickly by listening to others critically than by listening to themselves. Finally, such use of the lab facilities can help make the class more interesting for all students: first, imaginative groups of students can often construct amusing and interesting dialogs from the materials at hand (which textbooks writers seem to be unable to do), and secondly, almost every student enjoys hearing his own voice. This process can be expanded by hav. ing advanced level students write and act out on tape short stories, then play these stories for the lower level classes.

All of these creative uses of lab facilities are of course designed to make the class more interesting to the students by making them more responsible for what goes on in the class. Even if an ideal complete set of audio-visual materials is available-tapes, films, slides, and other realia of every sort-the effectiveness of these materials will be limited by the degree to which the student becomes an active participant in the work of the class. As long as he is merely the passive recipient of these potential experiences, his learning will be limited and his interest negligible. Ultimately the student is responsible for his own learning: the teacher can do no more than present the opportunity for the student to learn. Programmed materials 
assume that the student feels this responsibility, i.e. that he is sufficiently interested in the subject matter itself or he is sufficiently self-conscious that he does not want to fail. Thus, it is assumed that when the responsibility is thrown completely on the individual student, he will work energetically because he feels personally the pressure of this responsibility. Classroom observation of students in normal situations, however, tends to refute this supposition. Very few students in fact seem to have such a highly developed sense of self-identity that they feel compelled to accept this responsibility for their learning for the sake of personal benefit. The majority of these young people identify much more with the group than with themselves as individuals. Consequently, if the responsibility for the welfare of the group is cast on their shoulders, they are much more likely to be willing to take that responsibility seriously. So, when advanced classes understand that their work is to be used to help the beginning classes, and when smaller segments of the beginning classes realize that their efforts are to be used to help all members of the class, they will try much harder to do their jobs well. In doing their jobs well, of course, they learn.

Because of this general lack of self-awareness of the individual student, it is quite a moot point whether the ideal teacher-pupil ratio is one to one. In practice the best result usually occur when there is one teacher to a small group of five to ten students, for the students can interact among themselves with the teacher acting as a guide. If the number of students in the group becomes too large, of course, the majority have no chance to participate actively in class work and they lose their chance to learn. The lab can make it possible for the teacher to work with the small groups of students, so none get lost in the crush. The teacher can divide each class into three groups of equal size. Each group then spends a portion of each day working with tapes, a portion of each period working together on an assigned project, e.g. the construction of a dialog to be presented by the group, and a portion of each day working with the teacher. By use of such a technique we are able to break up the one-period block of time. This in turn offers other possibilities for effective teaching. For example, with this organizational plan it becomes possible to have students with varying abilities, or even at different levels of achievement, scheduled in the same classroom.

With the help of EFI four-channel wireless equipment it was possible to keep German in the curriculum of Edmonds Community College during its first two years of operation. Because of the relatively small initial enrollment in any given section, German would have had to be sacrificed for economic reasons. However, by using the techniques outlined above two, three, and even four different levels of German have been offered simultaneously. The students had the 


\section{Creative Lab}

benefits both of a programmed and traditional classroom course: they recognized their responsibility for their own learning, they worked together for their mutual benefit, and they had the services of the teacher available for individual problems for a portion of each session.

A similar program is being introduced into Edmonds High School. A further feature of the high school program is that at the end of the first half-semester those students who are not ready to progress to the next stage will start over again immediately, instead of having to wait until the next year. At the other end of the scale, those students in a given class who are able to do extra work will have that opportunity. Thus the program will be tailored to the needs of relatively small groups of students rather than being directed at some nonexistent norm. The student is graded and given credit on the completion of a given amount of work, not on his having completed that work within a specified period of time. Since the major cause of student hostility toward learning foreign language is simply that the student is not learning the language, i.e. he does not understand what is going on, we should expect to find an increase in student interest. His interest is further stimulated by his greater active participation in the work of the class as a whole.

The Edmonds High School German program includes the various elements outlined above. First come the professionally prepared tapes which accompany the text. Taped quizzes have been prepared to cover the individual structures and vocabulary introduced in each lesson-a total of almost sixty individual quizzes for the first year alone. These can be used both to evaluate progress and as diagnostic teaching devices. Short, simple fables and anecdotes have been taped locally for use to increase interest and to give students practice in listening to materials which they have not previously prepared. Also, some children's records imported from Germany are available for use later in the year. Finally, each group within each class prepares and tapes a short dialog each week. At the end of the year a small prize will be awarded for the most imaginative and best produced dialog from each group.

The term "language lab" has been used here in a very broad sense. Obviously, the program outlined above need not involve an elaborate inventory of equipment. The minimal requirements are a tape recorder and some method of attaching earphones to that tape recorder. In the simplest terms this can be a jack and a set of earphones attached to a tape recorder which is kept in the individual classroom. Somewhat more convenient, of course, is some kind of multi-channel equipment. It would seem, in fact, that a fully-equipped separate lab might be more difficult to use than a more basic arrangement, for if groups of students must be shuttled from one room 
to another, this costs valuable time. The less sophosticated equipment is also less subject to breakdown. Most important, though, is the recognition that expensive installations are not necessary in order to have an effective language program in which the lab is an integral part.

The lab is a valuable educational tool. But just as the ultimate effectiveness of any tool is dependent upon the skill and understanding of the craftsman who uses it, so the usefulness and flexibility of the lab is finally dependent upon the understanding and imagination of the teacher who uses it.

About the Author: Mr. Reinert is Language Lab Director at Edmonds High School, Edmonds, Washington. 